\title{
Postoperative Analgesia: Comparing Continuous Epidural Catheter Infusion of Local Anesthetic and Opioid and Continuous Wound Catheter Infusion of Local Anesthetic
}

\author{
Maria Cristina Simões de Almeida, TSA ${ }^{1}$, Giovani de Figueiredo Locks, TSA ², Horácio Pereira Gomes, TSA 2, \\ Guilherme Muriano Brunharo ${ }^{3}$, Ana Laura Colle Kauling ${ }^{4}$
}

\begin{abstract}
Summary: Almeida MCS, Locks GF, Gomes HP, Brunharo GM, Kauling ALC - Postoperative Analgesia: Comparing Continuous Epidural Catheter Infusion of Local Anesthetic and Opioid and Continuous Wound Catheter Infusion of Local Anesthetic.

Background and objectives: Continuous wound infusion has been investigated as a method of postoperative pain control and its efficacy has been demonstrated when compared to saline infusion. The objective of this study was to compare the quality of postoperative analgesia, the use of opioids as rescue analgesia, patient satisfaction, and the incidence of complications between epidural catheter infusion of local anesthetic and opioids and continuous wound infusion of local anesthetic.
\end{abstract}

Methods: Thirty-eight patients undergoing elective laparotomy under general anesthesia, randomly divided into two groups, participated in this study. Group I (Gl) received postoperative patient-controlled epidural analgesia (PCEA) with continuous infusion of ropivacaine and fentanyl, while Group II (GII) receive postoperative patient-controlled continuous wound catheter infusion of ropivacaine. In the postoperative period, the following parameters were assessed: quality of analgesia through the Visual Analogue Scale; use of rescue opioids; and adverse effects driving patient satisfaction.

Results: Decreased pain at rest and with movements $(p<0.05)$ and lower consumption of rescue opioids $(p<0.05)$ were observed in $G$ in all intervals evaluated, as well as greater patient satisfaction in the post anesthesia care unit (PACU). The incidence of complications was similar in both groups except for pruritus which prevailed in GI between $6(p<0.05)$ and $24(p<0.001)$ postoperative hours.

Conclusions: Postoperative analgesia with opioids and local anesthetics via PCEA was superior to the patient-controlled local anesthetic infusion into surgical wound. The incidence of side effects was similar in both groups.

Keywords: Analgesia, Patient controlled; Anesthesia, Local; Analgesia, Epidural; Wounds and Injuries; Pain, Postoperative.

Financial Support: Galênica Indústria and Comércio Internacional Ltda. and Life Sul Tecnologia Médica.

[Rev Bras Anestesiol 2011;61(3): 293-303] @Elsevier Editora Ltda.

\section{INTRODUCTION}

Tissue damage inherent to the surgical procedure usually results in acute postoperative pain, which in some cases may be very intense and with severe complications. Historically, pain treatment has low medical priority ${ }^{1}$ and an inadequate control of this symptom causes not only patient discomfort,

Received from Hospital Universitário Polydoro Ernani de São Thiago, Universidade Federal de Santa Catarina - (UFSC), Brazil.

1. Medical Degree from Universidade Johannes Gutenberg - Germany, Professor of Departamento de Anestesiologia of UFSC. Physician of Hospital Universitário of UFSC

2. TSA, Physician of Hospital Universitário of UFSC

3. Medical Student at UFSC

4. Medical Student at UFSC

Submitted on September 5, 2010.

Approved on December 7, 2010.

Correspondence to:

Dr. Guilherme Muriano Brunharo

Rua Profa Maria Flora Pausewang, $s / n^{\circ}$

Trindade

88040900 Caixa Postal 5199 - Florianópolis, SC, Brazil

E-mail: murianoguilherme@gmail.com.br but it can increase postoperative morbidity and the incidence of postoperative chronic pain ${ }^{2}$. Modern strategies for pain control after large surgeries involve different analgesic modalities, as no single method has proven to be effective and devoid of side effects ${ }^{3}$.

Epidural analgesia with local anesthetics and opioids is known for its efficacy, providing good pain control and, as a consequence, reduction in postoperative morbidity ${ }^{2}$. However, although rare some severe complications have been reported such as respiratory depression, epidural hematoma and abscess, besides occasional neurologic injuries ${ }^{4-6}$. Recently, continuous wound infusion of local anesthetics has been investigated as an alternative for postoperative pain control, and its efficacy has been proven when compared to saline infusion ${ }^{7-9}$. The objective of the present study was to compare the quality of postoperative analgesia, the use of rescue analgesia with opioids, patient satisfaction, and the incidence of complications between continuous epidural catheter infusion of local anesthetics and opioids, a technique established worldwide, and wound catheter infusion of local anesthetics, a more recent technique. 


\section{METHODS}

After approval of this randomized prospective study by the Human Research Ethics Committee and signing of the informed consent, two postoperative analgesia techniques were investigated in patients undergoing elective abdominal surgeries under general anesthesia.

Patients of both sexes, aged 18-75 years, admitted to hospital, undergoing elective abdominal surgeries under general anesthesia lasting over two hours and with an abdominal incision greater than $12 \mathrm{~cm}$ were included in this study. All patients were classified as ASA I, II, or III. Exclusion criteria were pregnant women or those who were breastfeeding, patients with body mass index equal or greater that $30 \mathrm{~kg} \cdot \mathrm{m}^{2}$, presence of significant preoperative abdominal or chest pain, use of opioids in the last 7 days prior to surgery, patients incapable of understanding pain scales, patients on anticoagulants or anti-platelet drugs, presence of infection in surgical wound or dorsal region, or allergy to any of the drugs used under the protocol.

Patients were randomized into two groups. In Gl all patients received postoperative patient-controlled epidural analgesia while in Gll they received patient-controlled wound infusion of local anesthetic.

All participants underwent a pre-anesthetic evaluation according to the routine of the institution. On the evening before the surgery, advantages and potential complications of the anesthetic technique corresponding to the group they would be allocated were explained and they signed the informed consent. The Visual Analogue Scale (VAS) was introduced to all patients. In the operating room, all participants were monitored with non-invasive blood pressure, pulse oximeter, capnography, electrocardiogram on derivations $V_{5}$ and $D_{\|}$, and peripheral nerve stimulator (TOF Watch - Organon ${ }^{\circledR}$ ). In Gl patients, a thoracolumbar epidural catheter was implanted with the administration of a bolus of 375 to $750 \mathrm{mg}$ of ropivacaine and $50-100 \mu \mathrm{g}$ of fentanyl.

All patients underwent general anesthesia with propofol, $2-3 \mathrm{mg} \cdot \mathrm{kg}^{-1}$ and continuous infusion of remifentanil, 0.1-0.4 $\mu \mathrm{g} \cdot \mathrm{kg}^{-1} \cdot \mathrm{min}^{-1}$. Rocuronium, 0.6-1 mg. $\mathrm{kg}^{-1}$, was used to facilitate tracheal intubation, with $10 \%$ of the initial dose repeated during the procedure as needed. Anesthesia was maintained with $50 \%$ oxygen and air, as well as remifentanil and sevoflurane with doses adjusted according to clinical demand, and controlled mechanical ventilation.

In Gl, after surgery the tubing of the elastomeric Accufuser plus ${ }^{\circledR}$ pump (Galênica ${ }^{\circledR}$, Indústria e Comércio Ltda., Rio de Janeiro, Brazil) was connected to the thoracolumbar catheter and the infusion was initiated. The drugs infused in Gl patients included: $0.75 \%$ ropivacaine $40 \mathrm{~mL}$, fentanyl $250 \mu \mathrm{g}$, and saline $33 \mathrm{~mL}$. The rate of infusion was $2 \mathrm{~mL} \cdot \mathrm{h}^{-1}$, but the patient could trigger a bolus of $2 \mathrm{~mL}$ at 15 -minutes intervals.

In Gll patients, after closing the peritoneum and aponeurosis the surgeon implanted two multiloculated catheters into surgical wound through an introducing needle, approximately $4 \mathrm{~cm}$ below the end of the incision, at the 4 and 8 o'clock positions. Catheters were placed between the recent sutured aponeurosis and the deepest portion of the subcutaneous tissue, along the entire incision. After surgical wound total closure, a $10 \mathrm{~mL}$ bolus of ropivacaine $0.2 \%$ was administered and the catheters were connected to an elastomeric pump. Continuous infusion was instituted immediately after the surgery while the patient was still anesthetized. The drug infused was ropivacaine $0.2 \%$ at a rate of $5 \mathrm{~mL} \cdot \mathrm{h}^{-1}$, and the patient could trigger a bolus of $2 \mathrm{~mL}$ at 15 -minute intervals.

To prevent postoperative nausea and vomiting patients in both groups received dexamethasone $10 \mathrm{mg}$ after anesthetic induction, and ondansetron $8 \mathrm{mg}$ at the end of the procedure. If at the end of the surgery the level of residual neuromuscular blockade, assessed by acceleromyometry was lower than TOF 0.9, patients received neostigmine, $0.04 \mathrm{mg} \mathrm{kg}^{-1}$. All patients were extubated with TOF $\geq 0.9$

To complement analgesia, all patients received clinical doses of non-steroidal anti-inflammatories and dypirone or paracetamol at fixed intervals, which were maintained until the end of assessments.

After surgery, patients were evaluated as follows: at the time of discharge from the post anesthesia care unit (PACU), and 6 and 24 hours after surgery. The VAS was used to evaluate the quality of analgesia in two situations: "pain at rest" - when the patient was restricted in bed, without moving him/herself; and "pain upon movements" - when he/she was asked to cough vigorously. Quality of anesthesia was also determined by the need of rescue analgesia, which consisted of intravenous opioids whenever the patient complained of pain. Tramadol and morphine were the drugs used. Their use was evaluated qualitatively (yes or no) by checking the medical records.

Patient satisfaction, quality of sleep, and whether the patient would agree to undergo the technique again in a future surgery were evaluated on the same periodicity. The first two items were graded from 1 to 4 points: unsatisfactory, regular, satisfactory, and excellent. The last item was evaluated qualitatively (yes or no).

Evaluation of undesirable effects and complications also followed the same periodicity, being recorded as "present" or "absent". The following side effects were part of this item: nausea and vomiting, pruritus, and urinary retention. Respiratory depression was defined as a respiratory rate lower than $12 \mathrm{bpm}$ in the intervals between data collection, recorded by the nursing staff on medical records. Hypotension was defined as a $20 \%$ fall in blood pressure of baseline values or systolic blood pressure lower than $90 \mathrm{mmHg}$ in the intervals between data collection, recorded by the nursing staff on the medical records.

The number of patients was based on the literature ${ }^{12}$. To detect a difference of approximately $30 \%$ between groups, assuming an alpha error of $0.5 \%$ and a beta error of $20 \%$, we estimated at 20 the required the number of patients in each group totaling 40 patients.

To determine the association among qualitative variables the Chi-square test was used. To investigate the differences among quantitative variables between groups the Student's $t$ test or, in case of repeated measurements, Analysis of 
Variance was used. The software Excel, version 5.0, and Epi Info 3.5.1 were used. A value of $p<0.05$ was considered significant.

\section{RESULTS}

A total of 39 patients agreed to participate in the study, and were divided into GI (19 patients) and GII (20 patients). However, one patient in Gll was excluded from the study due to early catheter disconnection.

As can be seen in Table I a significant difference between groups in gender and age was not observed. However, regarding physical status $\mathrm{Gl}$ had more patients classified as ASA III. Regarding the distribution of surgeries by specialty a significant difference between groups was not observed $(p=0.329)$.

Table I - Demographic Distribution of Patients and Physical Status According to ASA

\begin{tabular}{llll}
\hline Variable & $\begin{array}{l}\mathrm{Gl} \\
\mathrm{n}(\%)\end{array}$ & $\begin{array}{l}\text { Gll } \\
\mathrm{n}(\%)\end{array}$ & $\mathrm{p}$ \\
\hline Gender & & & \\
Male & $10(53)$ & $8(42)$ & 0.515 \\
Female & $9(47)$ & $11(58)$ & \\
Age & $55.7 \pm 10.7$ & $49.9 \pm 13$ & 0.117 \\
Physical status & & & \\
ASA I and II & $7(36.8)$ & $17(89.5)$ & 0.002 \\
ASA III & $12(63.2)$ & $2(10.5)$ & \\
\hline
\end{tabular}

Results expressed as Mean \pm Standard Deviation and percentage; GI: continuous patient-controlled epidural analgesia; Gll: continuous patient-controlled wound catheter infusion of local anesthetic.

Figures 1, 2, and 3 show the VAS pain values at rest and with movements, and the use of opioids as rescue analgesia, respectively. There was significant reduction in pain at rest and with movement, as well as decreased need for rescue analgesia in GI when compared to GII.

Data regarding patient satisfaction with the techniques and possible future use are shown in Figure 4. A statistical significance in favor of $\mathrm{Gl}$ was observed at the time of discharge from the PACU.

Sleep quality assessment in the first postoperative night showed a tendency to greater satisfaction in Gl, although without statistical significance. For $77.8 \%$ of patients in $\mathrm{Gl}$, sleep was classified as satisfactory or excellent while in Gll only $50 \%$ classified it similarly $(p=0.082)$.

Table II shows the complications and adverse events in Gl and GII. Except for pruritus, which was prevalent in GI from the sixth postoperative hour on, significant differences were not observed between both groups. Regarding evaluation of urinary retention, until the sixth postoperative hour all patients had a urinary catheter; therefore, data was not collected at

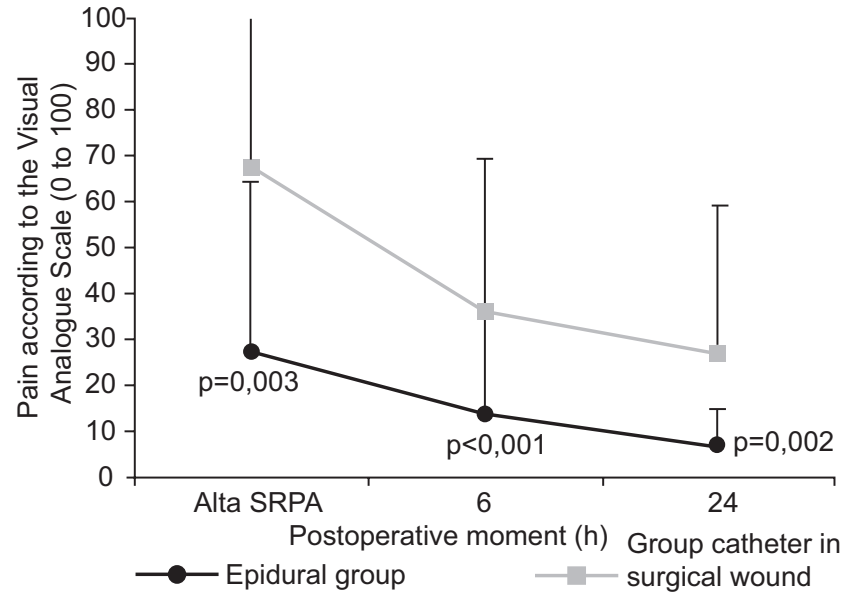

Figure 1 - Pain at Rest According to the VAS On Predetermined Postoperative Moments.

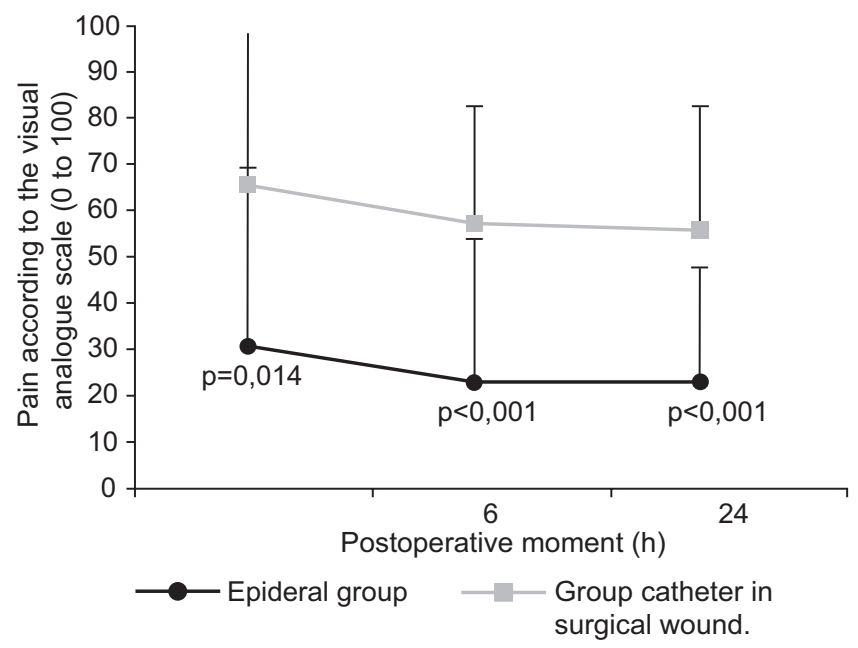

Figure 2 - Pain on Movement According to the VAS on Predetermined Postoperative Moments.

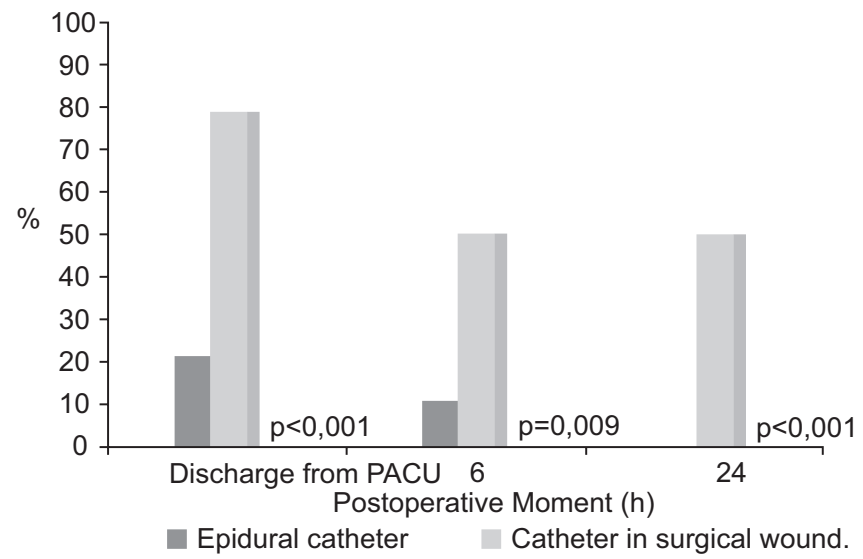

Figure 3 - Comparison of the Need for Rescue Analgesia with Opioids between Groups. 


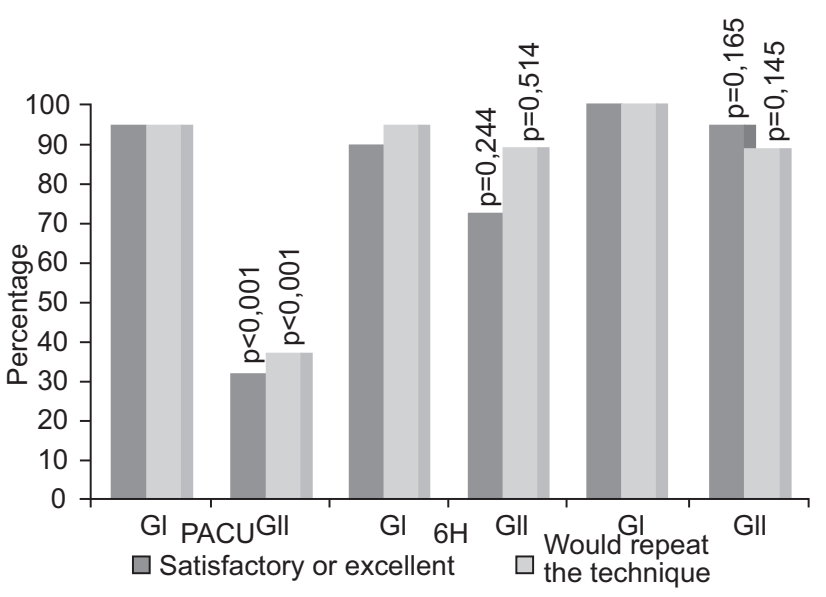

Figure 4 - Patient Satisfaction with the Technique and Percentage of Patients Who would repeat it.

Table II - Incidence of Complications and Side Effects

\begin{tabular}{llll}
\hline Side effects & Gl & Gll & \\
& & & $\mathrm{p}(\%)$ \\
\hline Nausea and vomiting & $\mathrm{n}(\%)$ & \\
PACU & $2(10.5)$ & $4(21.1)$ & 0.374 \\
$6 \mathrm{~h}$ & $2(10.5)$ & $5(27.8)$ & 0.181 \\
$24 \mathrm{~h}$ & $4(22.2)$ & $6(33.3)$ & 0.456 \\
Hypotension & & & \\
PACU & $0(0)$ & $0(0)$ & \\
6h & $1(5.3)$ & $0(0)$ & 0.324 \\
$24 \mathrm{~h}$ & $2(11.1)$ & $0(0)$ & 0.146 \\
Pruritus & & & \\
PACU & $1(5.3)$ & $0(0)$ & 0.311 \\
6h & $4(21.1)$ & $0(0)$ & 0.039 \\
$24 \mathrm{~h}$ & $9(50)$ & $0(0)$ & $<0.001$ \\
Urinary retention & & & \\
24h & $1(11.1)$ & $0(0)$ & 0.331 \\
\hline
\end{tabular}

GI: continuous patient-controlled epidural analgesia; GII: continuous patientcontrolled wound catheter infusion of local anesthetic; PACU: post anesthesia care unit

that moment. Twenty-four hours after surgery, the incidence was calculated regarding the number of patients whose catheter had been removed.

One patient in each group complained of severe pain at the site of catheter insertion during the interval between the first and sixth postoperative hour. In both cases, signs of inflammation as well as evidence of dislocation or malpositioning were not observed. The patient in Gl also did not show any neurological signs or symptoms. Drug infusion was discontinued immediately and the catheters were removed with significant improvement of pain.
In $\mathrm{Gl}$, one patient had a mild motor blockade in the right lower limb the day after surgery. Since this blockade did not hinder ambulation, it was not necessary to anticipate catheter removal.

Failures of infusion pumps were not observed during the study.

\section{DISCUSSION}

The present study demonstrated superiority of continuous patient-controlled epidural analgesia with ropivacaine and fentanyl when compared to continuous patient-controlled wound catheter infusion. The severity of postoperative pain was lower in the first group up to the $24^{\text {th }}$ postoperative hour, both at rest and forced coughing. The need for intravenous opioids as supplemental analgesia was also significantly lower in the group receiving epidural analgesia in all intervals evaluated. Besides, patients in this group reported better satisfaction indices and better sleep quality on the first night when compared to those who received continuous wound catheter infusion.

The objective of the present study was neither to compare equipotent doses of local anesthetics, nor the use of opioids, but to compare a well established technique with another more recent in the control of postoperative pain which does not use opioids.

There are several reasons for epidural anesthesia to be superior regarding other types of analgesia. Local anesthetics in the epidural space attenuate or block the entry of nociceptive stimuli in the central nervous system, and adding opioids results in a synergistic effect and potentiation of analgesia ${ }^{2}$. The efficacy of epidural analgesia in this study with a reduction in levels of pain scale and opioids consumption as rescue analgesia was compatible with the literature $2,10,11$.

The superiority of analgesia with epidural catheter when compared to systemic analgesia with opioids was recently demonstrated by two large meta-analyses. These studies demonstrated the superiority of epidural analgesia in all types of surgical procedures regardless of the drugs used, the type of infusion, location of the catheter, and moment of evaluation ${ }^{2,10}$. In one of the studies, two types of epidural analgesia were compared: continuous infusion and PCEA. The continuous infusion efficacy was statistically superior to PCEA, but not clinically superior since patients who underwent this technique showed a higher incidence of nausea and vomiting as well as motor blockades ${ }^{10}$.

The benefits of epidural analgesia are not limited to decreased postoperative pain and greater patient satisfaction. A recent review showed a reduction of cardiovascular complications especially in high risk patients and those undergoing complex procedures. Moreover, it also showed a decrease in postoperative pulmonary complications, infections, and respiratory failure. The study also indicated a faster recovery of intestinal function after abdominal surgeries with the use of epidural analgesia ${ }^{12}$.

Regarding the incidence of adverse events of epidural analgesia in our study, the incidence of nausea and vomiting was 
similar to that reported in large meta-analyses ${ }^{2,10}$. The incidence of hypotension was also similar, which was considered higher than the incidence reported in other large observational studies. Pruritus is one of the most common adverse events reported in literature, with an incidence of up to $60 \%{ }^{2,10}$. In our study, this was also the most common complication seen in $50 \%$ of patients in the evaluation 24 hours after surgery. However, in general this complication is usually well tolerated by patients and it has low morbidity. Motor blockade of the lower limbs, present in one patient in this study, is considered a significant adverse event because, in addition to causing discomfort, it may be an early sign of epidural hematoma in anticoagulated patients.

It has been demonstrate that postoperative analgesia with continuous wound catheter infusion of local anesthetics is effective in several types of surgical wound with low frequency of complications ${ }^{7-9,13}$. However, most studies have compared the method with saline infusion, and studies that comparing this method with postoperative analgesia with PCEA in abdominal surgeries are missing.

The objective of continuous wound catheter infusion of local anesthetics is to attenuated somatic nociceptive stimuli transmitted by nerve endings damaged by the surgical incision, including the activity of $\mathrm{C}$ fibers, with the consequent reduction of peripheral and central sensitization ${ }^{9}$. Besides, the infusion of fluids in the surgical wound can reduce the pain response through dilution or dispersion of histamine and vasoactive peptides ${ }^{3}$.

Studies evaluating the technique have not shown uniform results and the difference seems to lie in placement of catheters in the surgical wound. When catheter was placed deep in the subcutaneous tissue, only a discrete reduction in pain upon movements was observed on the first 24 postoperative hours when compared to the control group ${ }^{3}$. However, other studies obtained more positive results with deeper placement of the catheters $8,9,14,15$. The importance of the parietal peritoneum on the nociceptive stimuli generation was evident in studies placing catheters in the pre-peritoneal space, with reduction in pain severity at rest and with movements, as well as reduction in opioid consumption in the group receiving continuous infusion of local anesthetics 8,9 . Intraperitoneal placement of catheters was also evaluated and it presented satisfactory results, especially reducing rescue opioids consumption and the incidence of adverse events ${ }^{14,15}$.
A recent large quantitative and qualitative review of studies compared continuous catheter infusion of local anesthetics with saline infusion. The authors demonstrated the efficacy of the technique, with reduction of postoperative pain and use of opioids and their side effects, regardless of the type of surgery and location of catheters ${ }^{7}$.

Furthermore, note that regarding complications, most studies demonstrated that continuous wound catheter infusion of local anesthetics did not increase the incidence of infections or cellulitis, and there were no reports of systemic local anesthetic toxicity $7,9,14,15$. Regarding side effects, in the present study the group with catheters in the surgical wound showed higher incidence of nausea and vomiting after surgery, although without statistical significance. One can speculate that this effect was secondary to the increased need for rescue opioids in this group.

Although this study demonstrated the superiority of analgesia with PCEA when compared to continuous catheter wound infusion of local anesthetics, modern analgesia strategies suggest the combination of techniques and drugs to optimize control of postoperative pain. The combined use of different analgesia techniques that affect different phases of the painful stimulus modulation leads to a reduction in pain and lower consumption of drugs, therefore avoiding or decreasing the adverse effects of these drugs ${ }^{16}$. Taking into consideration the clinical conditions that limit the use of epidural catheters we can conclude that it is possible to find promising indications for continuous catheter wound infusion of local anesthetics especially in patients with increased risk for techniques that require access to the central nervous system.

Further investigations are necessary to determine the best placement of catheters in the surgical wound and the volume of local anesthetic infused.

The data of the present study indicate the superiority of postoperative analgesia with patient-controlled epidural analgesia of opioids and local anesthetics when compared to patient-controlled continuous wound catheter infusion of local anesthetics with catheters placed in the suprafascial location. Better results in favor of the epidural catheter were observed on the following parameters: severity of pain at rest and with movement, need of supplementary analgesia with opioids, and patient satisfaction in the PACU. The incidence of side effects was similar in both groups except for pruritus, which was more prevalent in the epidural group. 
13. Chiu KM, Wu CC, Wang MJ et al. - Local infusion of bupivacaine combined with intravenous patient-controlled analgesia provides better pain relief than intravenous patient-controlled analgesia alone in patients undergoing minimally invasive cardiac surgery. J Thorac Cardiovasc Surg, 2008;135:1348-1352.

14. Gupta A, Perniola A, Axelsson K et al. - Postoperative pain after abdominal hysterectomy: a double-blind comparison between placebo and local anesthetic infused intraperitoneally. Anesth Analg, 2004;99:1173-1179.

15. Perniola A, Gupta A, Crafoord K et al. - Intraabdominal local anaesthetics for postoperative pain relief following abdominal hysterectomy: a randomized, double-blind, dose-finding study. Eur J Anaesthesiol, 2009;26:421-429.

16. Forastiere E, Sofra M, Giannarelli D et al. - Effectiveness of continuous wound infusion of $0.5 \%$ ropivacaine by On-Q pain relief system for postoperative pain management after open nephrectomy. $\mathrm{Br} J$ Anaesth, 2008;101:841-847.

Resumen: Almeida MCS, Locks GF, Gomes HP, Brunharo GM, Kauling ALC - Analgesia Postoperatoria: Comparación entre la Infusión Continua de Anestésico Local y Opioide vía Catéter Epidural e Infusión Continua de Anestésico Local vía Catéter en la Herida Operatoria.

Justificativa y objetivos: La infusión continua de anestésicos locales en la herida quirúrgica, ha venido siendo investigada como un método en el control del dolor postoperatorio, habiendo sido demostrada su eficacia con relación a la infusión de solución fisiológica. El objetivo de este estudio, fue comparar la cualidad de la analgesia postoperatoria, el uso de opioides como analgesia de rescate, la satisfacción de los pacientes y la incidencia de complicaciones entre la utilización del anestésico local y el opioide vía catéter epidural, con la infusión continua de anestésico local en la herida operatoria.

Métodos: Se seleccionaron 38 pacientes sometidos a laparotomías electivas bajo anestesia general, que fueron distribuidos aleatoriamente en dos grupos. El Grupo I recibió como analgesia postoperatoria, ropivacaína y fentanil en infusión continua y controlada por el paciente por catéter epidural (PCEA), mientras que el Grupo II, fue con infusión continua y controlada por el paciente de ropivacaina, a través de catéter implantado en la herida operatoria. En el postoperatorio se evaluaron: la calidad de la analgesia por medio de la Escala Analógica Visual de Dolor; el uso de opioides de rescate y los efectos adversos de la satisfacción de los pacientes.

Resultados: Observamos la disminución del dolor en reposo y en movimiento $(p<0,05)$, y un menor consumo de opioides de rescate $(p<0,05)$, en el $\mathrm{Gl}$ en todos los intervalos evaluados, como también un mayor grado de satisfacción en la sala de recuperación postanestésica (SRPA). La incidencia de complicaciones fue similar entre los grupos con excepción del prurito, que prevaleció en el Gl entre 6 horas $(p<0,05)$ y 24 horas $(p<0,001)$ postoperatorias.

Conclusiones: La analgesia postoperatoria con opioide y el anestésico local vía PCEA, fue superior al uso de anestésico local en infusión continua y controlada por el paciente en la herida operatoria. La incidencia de efectos colaterales fue similar entre los grupos.

Descriptores: ANESTESIA, Local; EQUIPO: Cateter peridural; DOLOR: Postoperatorio; TÉCNICAS DE ANALGESIA: PCA Analgesia controlada por el paciente.

Ayuda Financiera: Galênica Indústria e Comércio Internacional Ltda. e Life Sul Tecnologia Médica. 